Review article

\title{
Evidence-based improvisation: Facing the challenges of cervical cancer care in Uganda
}

\author{
Megan Swanson ${ }^{\mathrm{a}, *}$, Stefanie Ueda ${ }^{\mathrm{a}}$, Lee-may Chen $^{\mathrm{a}}$, Megan J. Huchko ${ }^{\mathrm{b}}$, Carol Nakisige ${ }^{\mathrm{c}}$, \\ Jane Namugga ${ }^{\mathrm{d}}$ \\ ${ }^{a}$ Department of Obstetrics and Gynecology, Division of Gynecologic Oncology, University of California at San Francisco, United States \\ ${ }^{\mathrm{b}}$ Department of Obstetrics and Gynecology, Duke Global Health Institute, United States \\ ${ }^{\mathrm{c}}$ Division of Gynaecologic Oncology, Uganda Cancer Institute, Makerere University College for Health Sciences School of Medicine, United States \\ d Division of Gynaecologic Oncology, Mulago National Referral Hospital, Makerere University College for Health Sciences School of Medicine, Uganda
}

\begin{abstract}
A B S T R A C T
There is significant disparity in the prevalence of cervical cancer globally, with low- and middle-income countries (LMICs) shouldering a disproportionate share of disease incidence and an even greater proportion of morbidity and mortality. Available resources for diagnosis, treatment and palliation of cervical cancer are inversely related to per capita income. While prevention and screening remain public health priorities, given the large number of women affected by cervical cancer, expanding treatment capacity should be included in any evidence-based intervention plan. Uganda, a country with a high incidence of cervical cancer, serves as a representative case study in terms of the challenges of diagnosis and access to treatment in sub-Saharan Africa. Providers and patients in Uganda are challenged by late presentation to care, limited training opportunities, costprohibitive diagnostic studies, insufficient access to gold-standard treatment, and under-utilized palliative care services. This review highlights the ways in which Uganda's experience is typical of the continent at large, as well as areas where Uganda is unique. We describe the ways in which a small but dedicated group of gynecologists carefully use limited evidence and available resources creatively to provide the best possible care for their patients. We show that improvisation, albeit evidence-based, is central to the nature and success of oncology care in Africa (Livingston, 2012). We argue that a "recalibrated global response" (Farmer et al., 2010), particularly stressing the expansion of radiotherapy capabilities, could dramatically improve cancer care and outcomes for women in Uganda as well as in LMICs globally.
\end{abstract}

\section{Introduction}

Worldwide, there is great disparity in access to cancer treatment and outcomes. Despite the fact that low- and middle-income countries (LMICs) experience $78 \%$ of years of life lost (YLL) and $77 \%$ of disabilityadjusted life years (DALYs) due to cancer, these less-developed countries account for just $6 \%$ of total resources spent on cancer care globally (Beaulieu et al., 2009; Institute of Medicine Committee on Cancer Control in L, Middle-Income C, 2007). This gross funding discrepancy severely limits available treatment, which, together with typically advanced disease at diagnosis, contributes to the high mortality rates in LMICs.

Cervical cancer is the fourth most-common cancer among women worldwide with 528,000 new cases and 265,700 deaths estimated in 2012. Cervical cancer is over-represented in LMICs, where $84 \%$ of new cases and $87 \%$ of the deaths occur (Torre et al., 2015). Incidence in East Africa is among the highest in the world. In Uganda, cervical cancer is the most common malignancy and responsible for the greatest cancerrelated mortality among women with 3915 new cases and 2275 deaths annually (MOH, 2010; Bruni et al., 2016).

While incidence has decreased in developed countries secondary to widespread uptake of screening and vaccination, incidence of cervical cancer in Uganda, as well as in neighboring countries, has increased. Less than $10 \%$ of Ugandan women have ever been screened for cervical cancer (MOH, 2010; Ndejjo et al., 2016). Lack of screening is at least in part responsible for the magnitude of the cervical cancer epidemic in sub-Saharan Africa.

Although prevention is vital for cervical cancer control, treatment is also an essential part of any strategic intervention package (Gelband et al., 2016). Although comprehensive vaccination of pre-teen girls is

\footnotetext{
* Corresponding author at: Department of Obstetrics and Gynecology, Division of Gynecologic Oncology, University of California at San Francisco, Mission Hall, 7th Floor, Room 7444, Box 0132, 550 16th St, San Francisco, CA 94158, United States.

E-mail address: megan.swanson@ucsf.edu (M. Swanson).
} 
projected to be cost effective and lifesaving, incidence of cervical cancer would not be expected to drop for two decades, with maximal effect realized 50 years following comprehensive vaccination (Jit et al., 2014). Meanwhile, cervical dysplasia and early cancers will remain common and treatable. In those two decades before a benefit would be expected, approximately 11 million women in low-income countries will be diagnosed with cervical cancer (Atun et al., 2015). Treating these cancers improves survival and local control (Yap et al., 2017), palliates symptoms cost-effectively (Barton et al., 2003), and could even be cost-saving if scaled up to meet demand (Atun et al., 2015).

In Uganda, at least $80 \%$ of cervical tumors are diagnosed in an advanced stage (MOH, 2010). As a result, five-year overall survival (reported at a time when external beam radiation was available), for all cases is approximately $18 \%$ (Gondos et al., 2005). Lack of record keeping, attrition and the lack of systematized follow-up (MOH, 2010; Maranga et al., 2013; Mutyaba et al., 2009), all limit the accuracy of this estimate.

This paper gives an overview of the challenges providers and patients face when treating cervical cancer in Uganda. We will show how providers rely on evidence-based improvisation to design best-available treatment plans for their patients. Cervical cancer research is concentrated in high-income countries (Ginsburg et al., 2017); thus, findings must be extrapolated and adapted for use in low-resource settings. We will show the ways in which such improvisation can effectively solve problems as well as the ways in which it is limited. We will argue for expanding radiation in LMICs.

\section{Training}

In the United States, patients with gynecologic cancers have better outcomes when treated by gynecologic oncology subspecialists (DahmKahler et al., 2016), but there is a dearth of specialty-trained surgical and medical gynecologic oncologists in Africa, including Uganda (MOH, 2010). Formal gynecologic oncology training opportunities in sub-Saharan Africa are limited: three fellowships in Ethiopia, one in Ghana, one in Kenya, one in Zambia and several in South Africa (Johnston et al., 2017). The entire sub-Saharan portion of the continent has the capacity to train roughly as many fellows per year as the state of California. Funding for individual fellows is variable; as these programs are considered post-graduate degrees in East Africa, trainees must pay tuition averaging \$3500 US dollars (USD) per year (Dubowitz et al., 2010), three-times Uganda's average national annual income (UBOS, 2014).

In response to the high unmet need for surgeons trained to perform oncologic pelvic surgeries, one group of Canadian gynecologic oncologists, in partnership with the Society of Gynecologic Oncology of Canada and with local colleagues, has developed a focused high-intensity hands-on curriculum designed to train gynecologists in complex surgery including radical hysterectomy and lymphadenectomy (Elit et al., 2010). The program was piloted in Mongolia and implemented in Kenya, consisting of a 2-week course combining seven online teaching modules with hands-on surgical training in-country. Similar recurring 1-week training opportunities for a core group of gynecologists in radical hysterectomy and lymphadenectomy at publically-funded tertiary care hospitals in Kampala, Uganda have been offered by dedicated USbased gynecologic oncologists for several years.

Under the leadership of local senior gynecologists, Uganda is developing a fellowship program in gynecologic oncology. The fellowship will be a joint effort between the Uganda Cancer Institute and Mulago National Teaching and Referral Hospital with financial support from the African Development Bank (ADB). The ADB has recently designated Uganda as the regional Center of Excellence for oncology and has created funding opportunities for training through the newly-established East African Oncology Institute (East Africa Centers of Excellence Uganda, 2014). The fellowship will also draw support, mentorship and recurring hands-on in-county training from gynecologic oncologists stationed abroad. Organizations like the Society of Gynecologic Oncology and the International Gynecologic Cancer Society are recognizing the importance of formal training opportunities in LMICs and are investigating strategies to facilitate access to hands-on training.

\section{Diagnostic challenges}

\subsection{Imaging}

In addition to the lack of trained gynecologic oncologists, accurate diagnosis is limited by imaging capabilities. Despite the clinical-staging paradigm, diagnostic work-up in more-developed countries usually includes Computed Tomography (CT), Magnetic Resonance Imaging (MRI) and/or Positron Emission Tomography (PET) scans. These advanced imaging technologies can help detect lymph node metastases, frequently missed by clinical staging, which can significantly impact treatment planning (Bourgioti et al., 2016; Hansen et al., 2015). However, access to CT, MRI and PET technology is limited by costs and availability of machines in LMICs. While medical care has been offered free of charge at public facilities in Uganda since 2001, nearly half of the country's healthcare financing continues to come from out-ofpocket expenditures (Orem and Zikusooka, 2010). Patients must selfpay for some labs and all imaging and pathology studies. CT scans, costing at least as much as the average monthly national income (300,000 Ugandan Shillings, about \$80), are not feasible for most patients in Uganda.

By contrast, a pelvic ultrasound in Uganda is a more feasible expenditure (about 20,000 shillings or \$5). There are data to suggest that ultrasound can compare favorably to MRI in their ability to characterize tumor size, depth of invasion and parametrial infiltration (Epstein et al., 2013; Fischerova and Cibula, 2015; Fischerova et al., 2008). Thus, Ugandan gynecologists use physical exam, biopsy and ultrasound to inform staging and treatment planning for their patients.

\subsection{Pathology}

Pathology services are essential for diagnosis and treatment, as well as for accurate registries. However, service coverage in sub-Saharan Africa is, at best, one-tenth of the coverage of high-income countries (Adesina et al., 2013). While Uganda has a rich history of strong pathology scholarship, contributing to formative research on pathogenesis of Burkitt's Lymphoma (Walusansa et al., 2012), services are insufficient, with an estimated 1 pathologist for 1.5 million people (Nelson et al., 2016). Laboratories, equipment and staffing must increase to significantly improve capacity. While costs are substantial, a professional pathology group has devised a three-tiered laboratory system to standardize and streamline resources to provide full-spectrum oncology care in low resource settings: tier one lab start-up costs would be at least $\$ 25,000$, tier two $\$ 240,000$ and tier three $\$ 412,000$ (Warner, 2017).

Registries, which are essential for understanding the epidemiologic magnitude of disease in order to mobilize response, are not common in sub-Saharan Africa. Uganda has one of the only registries considered to be comprehensive on the continent, yet, nearly half (48\%) of cervical cancer cases captured by the Kampala Cancer Registry do not report a stage (Wabinga et al., 2003). Gynecology and pathology faculty at the Uganda Cancer Institute (UCI) and Mulago Hospital are creating new processes to standardize and improve two-way reporting.

As pathology services at government hospitals are congested, a network of private pathology labs have emerged in Kampala, Uganda. Quicker specimen processing and good-quality reporting come at a higher cost to patients. These private labs are variable in their commitment to reporting to the Kampala Cancer Registry. As with imaging and laboratory reports, patients serve as their own mobile medical record, transporting their own formalin-laden specimens to labs and then couriering reports to their treating physicians. 


\section{Treatment}

Surgery, radiation and chemotherapy are theoretically available in sub-Saharan Africa; however, multiple system obstacles often block access to one or more of these treatment modalities (Sullivan et al., 2015). In Uganda, the ever-changing landscape of available treatment options has made the development of straightforward protocols and consistent training opportunities impractical.

\subsection{Surgery}

Early-stage cervical cancer may be cured with radical hysterectomy, but is a rare diagnosis in Uganda. A successful trip to the operating room requires more than a scalpel and a surgeon. Apart from lack of trained and available surgeons (there is only one fellowship-trained gynecologic oncologist in Uganda) (Meara et al., 2016), there is also a significant shortage of trained anesthesia providers: in Uganda, there is one anesthesiologist for about every two million people (Dubowitz et al., 2010; Epiu et al., 2017). Comparatively, there is one anesthesiologist for every 4000 people in the United States (Egger Halbeis and Schubert, 2008). Additionally, there are severe shortages of essential anesthesia equipment (for example, government hospitals in Uganda do not typically have pulse oximetry) (LeBrun et al., 2014), protocols and intensive care unit services, challenging the already over-worked anesthesia staff (Epiu et al., 2017). In a recent Regional survey, none of the major teaching hospitals in East Africa, including Mulago, were able to meet the World Federation of the Societies of Anesthesiologists international guidelines for safe anesthesia (Epiu et al., 2017). Although Uganda attempts to address the unmet need for anesthesia services with non-physician "anesthetic officers" and nurse anesthetists, who provide the majority of anesthesia care unsupervised (Dubowitz et al., 2010), there remains a shortage of providers.

Surgeries are often delayed or cancelled at Mulago or UCI due to lack of available cross-matched blood. Despite recent improvement in the supply-side of the centrally managed blood bank in Uganda (Chevalier et al., 2016), whole blood collection remains insufficient relative to demand (Lund et al., 2013). At Mulago Hospital, cancerrelated anemia was the most common indication for transfusion (34\%), followed by acute blood loss from obstetric complications (12\%) (Butler et al., 2015). As demand already exceeds supply, obtaining units of whole blood for type and crossmatch pre-operatively is difficult. Bottlenecks in blood processing secondary to understaffing, broken equipment and overcrowding have resulted in significant delays from collection to dispatch from the bank; a considerable amount of blood must be discarded before reaching the hospital (Kajja et al., 2010), making a limited resource even more scarce.

\subsection{Radiation}

Radiotherapy with sensitizing chemotherapy is the treatment of choice for bulky early-stage disease as well as for locally- and regionally-advanced cervical cancer. About half of African countries have at least one radiation machine, utilizing mostly cobalt-60 isotopes as the radiation source, but distribution is not uniform: $60 \%$ of all radiotherapy equipment on the continent is located in the two highest-resourced countries: South Africa and Egypt (Abdel-Wahab et al., 2013).

Radiotherapy necessitates reliable electricity, a transportation/ highway system, security at the site of the source (especially for cobalt isotope sources), political stability, and specialized staff (Atun et al., 2015). Although difficult to quantify the magnitude of shortage, there is a significant paucity of radiation oncologists, medical physicists, radiation therapists, nurses and other staff in sub-Saharan Africa (Eriksen, 2017).

Low- and middle-income countries have the greatest unmet need for radiotherapy and, thus, the greatest potential for benefit with scale-up (Yap et al., 2017). Despite the expense, investing in expanding radiotherapy, would actually be cost-saving. Physicians, epidemiologists and health economists have argued that scaling up radiotherapy services over the next 20 years to meet worldwide demand could save 26.9 million life years in LMICs and economic benefits could total up to $\$ 278$ billion US dollars from productivity gains in that same time period, thus saving lives and money (Atun et al., 2015). Re-directing funds in this manner would represent a "recalibration" of the global response to the epidemic of cervical cancer in LMICs (Farmer et al., 2010).

Radiation can be standardized and delivered safely, even in basic settings (Atun et al., 2015). Linear accelerators (linacs) and cobalt-60 machines are both acceptable for the delivery of external beam radiotherapy, each with advantages and disadvantages. When compared to linacs, cobalt-60 machines have overall lower initial set-up and procurement costs and simpler staffing and maintenance (total cost estimate over 15 years $\$ 1,380,000$ compared to $\$ 2,160,000-3,600,000$ for linacs), but source exchange every five years and security can be complicated (Healy et al., 2017).

When Uganda had one functioning external beam machine, it was able to meet just $2.6 \%$ of the nation's indicated radiation treatments, even running the machine close to $20 \mathrm{~h}$ per day, representing one of the highest national unmet needs in the world (Abdel-Wahab et al., 2013; Datta et al., 2014). Uganda's cobalt source was overdue for an exchange and the retrofitted machine, with a long history of breakdowns since procurement from China in 1994 (Kigula Mugambe and Wegoye, 2000), was found to be broken beyond repair in March 2016 (BBC, 2016). Since that time, Uganda has been without external beam radiation.

Multiple factors challenged Uganda's ability to exchange its cobalt source and obtain a new machine in a timely fashion. Worldwide, exchanging radiation sources has become increasingly difficult, in the past decade and a half. Although the United Nation's International Atomic Energy Agency (IAEA) works with LMICs to assist with procurement, shipment and decommission, mobility of radioactive material on commercial airlines has been severely constrained since the September 11, 2001 terrorist attack in New York and the ensuing War on Terror (IAEA, 2003).

On the continent, brachytherapy is generally more limited than external beam radiotherapy, available in only 20 of 52 African countries, also with considerable disparity in distribution (Abdel-Wahab et al., 2013). The opposite situation exists in Uganda, where brachytherapy via a cobalt-60 HDR machine is available. However, with no external beam capabilities currently, in this setting brachytherapy is used as for palliation in advanced cervical cancer.

\subsection{Chemotherapy}

Chemotherapy may be used concurrently with radiation in locallyand regionally-advanced disease, for primary treatment of metastatic disease, as well as in adjuvant and neoadjuvant treatment of cervical cancer. Availability of chemotherapeutic agents is variable in East Africa and on the continent at large. A survey of chemotherapy used most-commonly in pediatric cancers found that public facilities in Africa had a median of 9 of 18 essential chemotherapeutics (Barr and Robertson, 2016). The Uganda Cancer Institute (UCI) provides chemotherapy free of charge, but availability of various cytotoxic medications varies. Cisplatin is usually available at the UCI pharmacy, but paclitaxel and carboplatin, are rarely available. If UCI's stocks are depleted, patients may purchase these drugs at private pharmacies (approximately 300,000 Ugandan shillings or $\$ 80$ per drug per cycle, often planning for three to six cycles in total) and bring them to the Institute for mixing and administration. Cycles may be delayed or proceed without all prescribed drugs, depending on circumstances.

With a limited number of trained medical oncologists in Uganda, running an infusion center has required innovative task-shifting, as has been demonstrated safe and effective in neighboring countries (Tapela et al., 2016). A team of pharmacists, clinical officers (mid-level 
providers with formal training similar to that of a physician assistant in the United States) and nurses run the chemotherapy unit, under supervision of a small team of medical oncologists.

The infusion room at the Uganda Cancer Institute, the only public facility in the country providing chemotherapy, is small, often overcrowded, with a single row of hard plastic chairs with intervening IV poles. Steroids are typically provided as anti-emetics. Labs are checked earlier in the day, with results hand-carried by the patients for review by the on-duty clinical officer immediately prior to chemo administration. Granulocyte colony stimulating factor is not generally available, thus, marrow suppression often results in a dose-reduction or delay.

As most cancer patients in East Africa, including Uganda, present with advanced stage disease (Sankaranarayanan et al., 2010), curative treatment is often not possible, especially with limited or no access to radiation. A study of chemotherapy use patterns at the Uganda Cancer Institute found that $45 \%$ of patients with terminal cancers received chemotherapy in the last 30 days of life (Low et al., 2017). While endof-life chemotherapy is not associated with survival benefit and may actually cause harm (Prigerson et al., 2015; Saito et al., 2011; Zdenkowski et al., 2013), cultural and practical factors have contributed to its usage in Uganda. Doctors reported using performance status, cancer stage, and perceived tumor chemotherapy sensitivity, as well as non-clinical factors like patient expectations and lack of outcome data to determine whether to prescribe chemotherapy (Low et al., 2017). These findings may be reflective of patterns in the region, suggesting a need for evidence-based guidelines for end-of life chemotherapy usage.

\subsection{Improvisation}

Given resource limitations, improvisation based on available evidence is central to the nature and success of oncology care in Africa (Livingston, 2012). With external beam radiotherapy currently unavailable in Uganda, providers must consider resources and extrapolate evidence, mostly from high-income countries producing $73 \%$ of cervical cancer research (Ginsburg et al., 2017), in order to synthesize bestavailable treatment plans. Without radiation, providers rely on tools at hand, including chemotherapy and hysterectomy, a strategy supported by the ASCO Resource-stratified Treatment Guidelines (Chuang et al., 2016).

Data from several randomized trials and a meta-analysis suggest that neoadjuvant chemotherapy followed by radical hysterectomy may be equivalent to primary treatment with radiation and weekly cisplatin (chemoradiation), the standard of care for locally and regionally advanced disease (Benedetti-Panici et al., 2002; Chang et al., 2000; Kokka et al., 2015). However, due to the confounding effect of radiotherapy (in all cited trials, women with high-risk histologic features on hysterectomy underwent adjuvant radiotherapy), it is difficult to extrapolate findings to low-resource settings with poor or no access to radiotherapy. Additionally, there are two ongoing phase III randomized clinical trials comparing neoadjuvant chemotherapy followed by radical hysterectomy to chemoradiation in patients with bulky early-stage or locally advanced disease, one in Europe and one in India.

In the absence of radiotherapy, gynecologists and medical oncologists at Uganda Cancer Institute have jointly developed a treatment protocol for locally and regionally-advanced cervical cancer based on above-referenced data. Women with bulky IB2-IIA tumors who are not radical hysterectomy candidates based on surgeon consensus and stage IIB-IIIB disease are treated with neoadjuvant chemotherapy, three to six cycles of cisplatin and paclitaxel, with re-evaluation for radical hysterectomy. If government stocks of paclitaxel are depleted, patients are encouraged to obtain it from private pharmacies, otherwise singleagent cisplatin is typically used. Several successful radical hysterectomies have been performed after neoadjuvant chemotherapy. If patients have not significantly responded after 3 cycles, they may be continued on chemotherapy, considered for palliative brachytherapy if symptomatically bleeding, or possibly referred for hospice. Ugandan research teams are tracking these cases.

Another option altogether is to obtain radiotherapy abroad. Following irreparable breakdown of the machine, Aga Khan, a private hospital in Nairobi, Kenya, $650 \mathrm{~km}$ from Kampala, Uganda pledged to provide radiation treatments free of charge to 400 of the estimated 17,000 Ugandan patients needing radiation at that time. The Ugandan Ministry of Health pledged to provide transportation and accommodation for those selected for treatment (Mugerwa, 2016). The total out-of-pocket expenses for a woman obtaining five weeks of radiation treatments for cervical cancer, including transportation, accommodation and living expenses in Nairobi, total approximately $\$ 5000$, unaffordable for most Ugandans (Nelson, 2017). It is unclear how many patients have benefitted from this program, nor how the Ministry of Health ultimately selected the patients. The multidisciplinary Gynecologic Oncology Tumor Board at the UCI was tasked with recommending patients for treatment in Nairobi, though no specific number of spots for cervical cancer was ever designated. The Tumor Board reviewed dozens of cases according to equity criteria developed by the World Health Organization to assist in rationing limited health interventions (Norheim OF et al., 2014). Cases mostly likely to benefit from treatment, interpreted to mean those with the greatest chance of cure, were prioritized.

\section{Palliative care and hospice}

Given the insufficient capacity to provide treatment to most women diagnosed with late-stage cervical cancer in low-income countries, the WHO recommends a focus on palliative care (WHO, 2013). Even in maximal resource settings, we know that patients provided with early palliative care have improved quality of life and mood and may even survive longer than their counterparts (Temel et al., 2010; Temel et al., 2017; Ferrell et al., 2017). Availability of palliative care is limited, less than a quarter of African countries have access to palliative care services (Merriman and Harding, 2010; Harding et al., 2013). Fortunately, Uganda has offered palliative care and hospice services in partnership with a non-profit organization, Hospice Africa Uganda, since 1993.

Pain control at the end of life, an essential component of palliative care, has been prioritized in Uganda. Affordable morphine powder, which is reconstituted to liquid, has been subsidized by the government since 1993 (Merriman and Harding, 2010). Nevertheless, just 40\% of government hospitals reportedly have access to narcotic pain medication (LeBrun et al., 2014). In order to increase access to opiates, Uganda liberalized prescribing laws in 2002. Nurses trained by Hospice Africa Uganda and registered with the state can prescribe morphine for terminally ill patients, a novel approach to expand the pool of providers who could offer such services (Harding et al., 2013).

In Uganda, hospice services are usually provided in a patient's home, using an extensive network of community volunteer workers throughout the country, as tends to be the cultural preference (Jack et al., 2011). Hospice Africa Uganda staff and volunteers work with terminally ill patients' families, instructing safe liquid morphine reconstitution and administration, in addition to other interventions according to the hospice philosophy (Harding et al., 2013; Jack et al., 2011). The oral morphine program is safe and serves as a model to other sub-Saharan African countries, though there is some evidence of an unmet need for palliative care services among women with cervical cancer (Logie and Harding, 2005; Clark et al., 2007; Mwaka et al., 2013).

\section{Conclusions}

Faculty at Uganda Cancer Institute and Mulago National Referral Hospital, the country's two publically-funded hospitals providing specialized gynecologic cancer care, are collaboratively developing 
treatment protocols that creatively use available resources according to limited evidence in order to provide the best possible care for women with cervical cancer, especially while external beam radiation remains unavailable. Interdisciplinary partnerships with multidisciplinary teams in medical oncology, radiation oncology, pathology and palliative care teams have relied on task-shifting in order to maximize the capacity to care for many patients. Uganda's challenges with cervical cancer care are typical for the region and the continent at large. Flexibility in the face of adversity, evidence-based improvisation through treatment strategies and teamwork across disciplines have been vital to the success of oncology care at UCI and Mulago. As oncology care continues to evolve, it will be key to track outcomes to measure the relative success of these various treatment strategies.

LMICs are burdened by a disproportionate amount of cervical cancer, hence the use of a "clinical staging" paradigm. Despite that recognition, resources for diagnosis and treatment of cervical cancer care are disproportionately found in high-income countries with relatively less disease burden. Efforts by a small dedicated multidisciplinary team in Uganda have demonstrated that cervical cancer care is possible, even in low-resource settings, but without adequate funding from the World Bank, the African Development Bank, cross-national NGOs, academic research funds, and in-country national budgets, improvisation can only go so far.

High-quality trials, years of data and expert consensus have established so-called "gold standard" treatments for cervical cancer. While there are some data to suggest limited efficacy of alternative treatments, there is simply no substitute for external beam radiation in eradicating locally- and regionally-advanced cervical tumors. Without either a colbalt-60 or linear accelerator machine, no amount of improvisation is likely to yield comparable results.

The international community has the opportunity to recalibrate its response to meet the need for cervical cancer treatment worldwide. A substantial increase in funding to expand training opportunities for clinicians and treatment modalities for radiotherapy is needed and will only become more critical as the burden of cancer continues to shift to poor countries.

\section{Conflicts of interest}

No conflict of interest.

\section{References}

Abdel-Wahab, M., Bourque, J.M., Pynda, Y., Izewska, J., Van der Merwe, D., Zubizarreta, E., et al., 2013. Status of radiotherapy resources in Africa: an International Atomic Energy Agency analysis. Lancet Oncol. 14, e168-75.

Adesina, A., Chumba, D., Nelson, A.M., Orem, J., Roberts, D.J., Wabinga, H., et al., 2013. Improvement of pathology in sub-Saharan Africa. Lancet Oncol. 14, e152-7.

Atun, R., Jaffray, D.A., Barton, M.B., Bray, F., Baumann, M., Vikram, B., et al., 2015. Expanding global access to radiotherapy. Lancet Oncol. 16, 1153-1186.

Barr, R., Robertson, J., 2016. Access to cytotoxic medicines by children with cancer: a focus on low and middle income countries. Pediatr. Blood Cancer 63, 287-291.

Barton, M.B., Jacob, S.A., Gebsky, V., 2003. Utility-adjusted analysis of the cost of palliative radiotherapy for bone metastases. Australas. Radiol. 47, 274-278.

BBC, 2016. Uganda's Radiotherapy Machine for Cancer Treatment Breaks. http://www. bbc.com/news/world-africa-35997075.

Beaulieu, N.B.D., Bloom, R., Stein, R., 2009. Breakaway: the global burden of cancer challenges and opportunities. In: A Report From the Economist Inteligence Unit, . http://graphics.eiu.com/upload/eb/EIU_LIVESTRONG_Global_Cancer_Burden.pdf $(3 / 27 / 17)$.

Benedetti-Panici, P., Greggi, S., Colombo, A., Amoroso, M., Smaniotto, D., Giannarelli, D., et al., 2002. Neoadjuvant chemotherapy and radical surgery versus exclusive radiotherapy in locally advanced squamous cell cervical cancer: results from the Italian multicenter randomized study. J. Clin. Oncol. Off. J. Am. Soc. Clin. Oncol. 20, 179-188.

Bourgioti, C., Chatoupis, K., Moulopoulos, L.A., 2016. Current imaging strategies for the evaluation of uterine cervical cancer. World J. Radiol. 8, 342-354.

Bruni, L.B.-R.L., Albero, G., Aldea, M., Serrano, B., Valencia, S., Brotons, M., Mena, M. Cosano, R., Muñoz, J., Bosch, F.X., de Sanjosé, S., Castellsagué, X., 2016. Human papillomavirus and related diseases in Uganda. In: Summary Report 2016-02-26. ICO Information Centre on HPV and Cancer (HPV Information Centre) (21/08/2016).

Butler, E.K., Hume, H., Birungi, I., Ainomugisha, B., Namazzi, R., Ddungu, H., et al., 2015.
Blood utilization at a national referral hospital in sub-Saharan Africa. Transfusion 55, 1058-1066.

Chang, T.C., Lai, C.H., Hong, J.H., Hsueh, S., Huang, K.G., Chou, H.H., et al., 2000. Randomized trial of neoadjuvant cisplatin, vincristine, bleomycin, and radical hysterectomy versus radiation therapy for bulky stage IB and IIA cervical cancer. J. Clin. Oncol. Off. J. Am. Soc. Clin. Oncol. 18, 1740-1747.

Chevalier, M.S., Kuehnert, M., Basavaraju, S.V., Bjork, A., Pitman, J.P., 2016. Progress toward strengthening National Blood Transfusion Services - 14 countries, 2011-2014. MMWR Morb. Mortal. Wkly Rep. 65, 115-119.

Chuang, L.T., Temin, S., Camacho, R., Dueñas-Gonzalez, A., Feldman, S., Gultekin, M., et al., 2016. Management and care of women with invasive cervical cancer: American society of clinical oncology resource-stratified clinical practice guideline. J. Global Oncol. 2, 311-340.

Clark, D., Wright, M., Hunt, J., Lynch, T., 2007. Hospice and palliative care development in Africa: a multi-method review of services and experiences. J. Pain Symptom Manag. 33, 698-710

Dahm-Kahler, P., Palmqvist, C., Staf, C., Holmberg, E., Johannesson, L., 2016. Centralized primary care of advanced ovarian cancer improves complete cytoreduction and survival - a population-based cohort study. Gynecol. Oncol. 142, 211-216.

Datta, N.R., Samiei, M., Bodis, S., 2014. Radiation therapy infrastructure and human resources in low- and middle-income countries: present status and projections for 2020. Int. J. Radiat. Oncol. Biol. Phys. 89, 448-457.

Dubowitz, G., Detlefs, S., McQueen, K.A., 2010. Global anesthesia workforce crisis: a preliminary survey revealing shortages contributing to undesirable outcomes and unsafe practices. World J. Surg. 34, 438-444.

East Africa Centers of Excellence Uganda, 2014. African Development Bank. https:// www.afdb.org/en/projects-and-operations/project-portfolio/p-z1-ib0-024/.

Egger Halbeis, C.B., Schubert, A., 2008. Staffing the operating room suite: perspectives from Europe and North America on the role of different anesthesia personnel. Anesthesiol. Clin. 26, 637-663 (vi).

Elit, L.M., Rosen, B., Jimenez, W., Giede, C., Cybulska, P., Sinasac, S., et al., 2010. Teaching cervical cancer surgery in low- or middle-resource countries. Int. J. Gynecol. Cancer 20, 1604-1608.

Epiu, I., Tindimwebwa, J.V., Mijumbi, C., Chokwe, T.M., Lugazia, E., Ndarugirire, F. et al., 2017. Challenges of anesthesia in low- and middle-income countries: a crosssectional survey of access to safe obstetric anesthesia in East Africa. Anesth. Analg. 124, 290-299.

Epstein, E., Testa, A., Gaurilcikas, A., Di Legge, A., Ameye, L., Atstupenaite, V., et al., 2013. Early-stage cervical cancer: tumor delineation by magnetic resonance imaging and ultrasound - a European multicenter trial. Gynecol. Oncol. 128, 449-453.

Eriksen, J.G., 2017. Postgraduate education in radiation oncology in low- and middleincome countries. Clin. Oncol. 29, 129-134.

Farmer, P., Frenk, J., Knaul, F.M., Shulman, L.N., Alleyne, G., Armstrong, L., et al., 2010. Expansion of cancer care and control in countries of low and middle income: a call to action. Lancet 376, 1186-1193.

Ferrell, B.R., Temel, J.S., Temin, S., Alesi, E.R., Balboni, T.A., Basch, E.M., et al., 2017. Integration of palliative care into standard oncology care: American society of clinical oncology clinical practice guideline update. J. Clin. Oncol. Off. J. Am. Soc. Clin. Oncol. 35, 96-112.

Fischerova, D., Cibula, D., 2015. Ultrasound in gynecological cancer: is it time for reevaluation of its uses? Curr. Oncol. Rep. 17 (28).

Fischerova, D., Cibula, D., Stenhova, H., Vondrichova, H., Calda, P., Zikan, M., et al., 2008. Transrectal ultrasound and magnetic resonance imaging in staging of early cervical cancer. Int. J. Gynecol. Cancer 18, 766-772.

Gelband, H., Sankaranarayanan, R., Gauvreau, C.L., Horton, S., Anderson, B.O., Bray, F., et al., 2016. Costs, affordability, and feasibility of an essential package of cancer control interventions in low-income and middle-income countries: key messages from Disease Control Priorities, 3rd ed. Lancet 387, 2133-2144.

Ginsburg, O., Badwe, R., Boyle, P., Derricks, G., Dare, A., Evans, T., et al., 2017. Changing global policy to deliver safe, equitable, and affordable care for women's cancers. Lancet 389, 871-880.

Gondos, A., Brenner, H., Wabinga, H., Parkin, D.M., 2005. Cancer survival in Kampala, Uganda. Br. J. Cancer 92, 1808-1812.

Hansen, H.V., Loft, A., Berthelsen, A.K., Christensen, I.J., Hogdall, C., Engelholm, S.A., 2015. Survival outcomes in patients with cervical cancer after inclusion of PET/CT in staging procedures. Eur. J. Nucl. Med. Mol. Imaging 42, 1833-1839.

Harding, R., Selman, L., Powell, R.A., Namisango, E., Downing, J., Merriman, A., et al., 2013. Research into palliative care in sub-Saharan Africa. Lancet Oncol. 14, e183-8.

Healy, B.J., van der Merwe, D., Christaki, K.E., Meghzifene, A., 2017. Cobalt-60 machines and medical linear accelerators: competing technologies for external beam radiotherapy. Clin. Oncol. 29, 110-115.

IAEA, 2003. Refusing Radioactive Material Shipments for Transport by Air. In: VIII T, editor. http://www.icao.int/safety/DangerousGoods/Working.Group of the Whole/ IP08 Att.pdf (4/7/2017).

Institute of Medicine Committee on Cancer Control in L, Middle-Income C, 2007Institute of Medicine Committee on Cancer Control in L, Midd. The national academies collection: reports funded by National Institutes of Health. In: Sloan, F.A., Gelband, H. (Eds.), Cancer Control Opportunities in Low- and Middle-income Countries. National Academies Press (US) National Academy of Sciences, Washington (DC).

Jack, B.A., Kirton, J., Birakurataki, J., Merriman, A., 2011. 'A bridge to the hospice': the impact of a community volunteer programme in Uganda. Palliat. Med. 25, 706-715.

Jit, M., Brisson, M., Portnoy, A., Hutubessy, R., 2014. Cost-effectiveness of female human papillomavirus vaccination in 179 countries: a PRIME modelling study. Lancet Glob. Health 2, e406-14.

Johnston, C., Ng, J.S., Manchanda, R., Tsunoda, A.T., Chuang, L., 2017. Variations in gynecologic oncology training in low (LIC) and middle income (MIC) countries 
(LMICs): common efforts and challenges. Gynecol. Oncol. Rep. 20, 9-14.

Kajja, I., Kyeyune, D., Bimenya, G.S., Sibinga, C.T., 2010. Bottlenecks of blood processing in Uganda. Transf. Med. (Oxford, England) 20, 329-336.

Kigula Mugambe, J.B., Wegoye, P., 2000. Pattern and experience with cancers treated with the Chinese GWGP80 cobalt unit at Mulago Hospital, Kampala. East Afr. Med. J. 77, 523-525.

Kokka, F., Bryant, A., Brockbank, E., Powell, M., Oram, D., 2015. Hysterectomy with radiotherapy or chemotherapy or both for women with locally advanced cervical cancer. In: The Cochrane Database of Systematic Reviews, (Cd010260).

LeBrun, D.G., Chackungal, S., Chao, T.E., Knowlton, L.M., Linden, A.F., Notrica, M.R., et al., 2014. Prioritizing essential surgery and safe anesthesia for the Post-2015 development agenda: operative capacities of 78 district hospitals in 7 low- and middleincome countries. Surgery 155, 365-373.

Livingston, J., 2012. Improvising Medicine: An African Oncology Ward in an Emerging Cancer Epidemic. Duke University Press, Durham \& London.

Logie, D.E., Harding, R., 2005. An evaluation of a morphine public health programme for cancer and AIDS pain relief in Sub-Saharan Africa. BMC Public Health 5 (82).

Low, D., Merkel, E.C., Menon, M., Lyman, G.H., Ddungu, H., Namukwaya, E., et al., December 2017. Chemotherapy use at the end of life in Uganda. J. Global Oncol. 3 (6), 711-719. http://dx.doi.org/10.1200/JGO.2016.007385. (0:JGO.2016.007385 PMID 29244988)

Lund, T.C., Hume, H., Allain, J.P., McCullough, J., Dzik, W., 2013. The blood supply in sub-Saharan Africa: needs, challenges, and solutions. Transf. Apheres. Sci. 49, 416-421.

Maranga, I.O., Hampson, L., Oliver, A.W., Gamal, A., Gichangi, P., Opiyo, A., et al., 2013. Analysis of factors contributing to the low survival of cervical cancer patients undergoing radiotherapy in Kenya. PLoS One 8, e78411.

Meara, J.G., Leather, A.J., Hagander, L., Alkire, B.C., Alonso, N., Ameh, E.A., et al., 2016. Global surgery 2030: evidence and solutions for achieving health, welfare, and economic development. Int. J. Obstet. Anesth. 25, 75-78.

Merriman, A., Harding, R., 2010. Pain control in the African context: the Ugandan introduction of affordable morphine to relieve suffering at the end of life. Philos. Ethics Humanit. Med. 5, 10.

MOH, 2010. Strategic Plan for Cervical Cancer Prevention and Control in Uganda, 2010-2014. Ministry of Health, Kampala, Uganda.

Mugerwa, Y., 2016. Govt to Airlift 400 Cancer Patients to Kenya. Daily Monitor, Kampala, Uganda. http://www.monitor.co.ug/News/National/Govt-to-airlift-400-cancerpatients-to-Kenya/-/688334/3159770/-/11sqwrsz/-/index.html (August 19, 2017).

Mutyaba, T., Mirembe, F., Sandin, S., Weiderpass, E., 2009. Male partner involvement in reducing loss to follow-up after cervical cancer screening in Uganda. Int. J. Gynaecol. Obstet. 107, 103-106.

Mwaka, A.D., Wabinga, H.R., Mayanja-Kizza, H., 2013. Mind the gaps: a qualitative study of perceptions of healthcare professionals on challenges and proposed remedies for cervical cancer help-seeking in post conflict northern Uganda. BMC Fam. Pract. 14 (193).

Ndejjo, R., Mukama, T., Musabyimana, A., Musoke, D., 2016. Uptake of cervical cancer screening and associated factors among women in rural Uganda: a cross sectional study. PLoS One 11, e0149696.

Nelson, K.G., 2017. Waiting to Die: Uganda's Untreated Cancer Patients. Aljazeera. http://www.aljazeera.com/indepth/inpictures/2017/03/waiting-die-ugandauntreated-cancer-patients-170306090150882.html (August 19, 2017).

Nelson, A.M., Milner, D.A., Rebbeck, T.R., Iliyasu, Y., 2016. Oncologic care and pathology resources in Africa: survey and recommendations. J. Clin. Oncol. Off. J. Am. Soc. Clin. Oncol. 34, 20-26.

Norheim OF, Baltussen, R., Johri, M., Chisholm, D., Nord, E., Brock, D., et al., 2014 Guidance on priority setting in health care (GPS-health): the inclusion of equity criteria not captured by cost-effectiveness analysis. Cost Eff. Res. Alloc. 12, 18.

Orem, J.N., Zikusooka, C.M., 2010. Health financing reform in Uganda: how equitable is the proposed National Health Insurance scheme? Int. J. Equity Health 9, 23.

Prigerson, H.G., Bao, Y., Shah, M.A., Paulk, M.E., LeBlanc, T.W., Schneider, B.J., et al., 2015. Chemotherapy use, performance status, and quality of life at the end of life. JAMA Oncol. 1, 778-784.

Saito, A.M., Landrum, M.B., Neville, B.A., Ayanian, J.Z., Earle, C.C., 2011. The effect on survival of continuing chemotherapy to near death. BMC Palliat. Care 10 (14).

Sankaranarayanan, R., Swaminathan, R., Brenner, H., Chen, K., Chia, K.S., Chen, J.G., et al., 2010. Cancer survival in Africa, Asia, and Central America: a population-based study. Lancet Oncol. 11, 165-173.

Sullivan, R., Alatise, O.I., Anderson, B.O., Audisio, R., Autier, P., Aggarwal, A., et al., 2015. Global cancer surgery: delivering safe, affordable, and timely cancer surgery. Lancet Oncol. 16, 1193-1224.

Tapela, N.M., Mpunga, T., Hedt-Gauthier, B., Moore, M., Mpanumusingo, E., MJ, Xu, et al., 2016. Pursuing equity in cancer care: implementation, challenges and preliminary findings of a public cancer referral center in rural Rwanda. BMC Cancer 16 (237)

Temel, J.S., Greer, J.A., Muzikansky, A., Gallagher, E.R., Admane, S., Jackson, V.A., et al., 2010. Early palliative care for patients with metastatic non-small-cell lung cancer. N. Engl. J. Med. 363, 733-742.

Temel, J.S., Greer, J.A., El-Jawahri, A., Pirl, W.F., Park, E.R., Jackson, V.A., et al., 2017. Effects of early integrated palliative care in patients with lung and GI cancer: a randomized clinical trial. J. Clin. Oncol. Off. J. Am. Soc. Clin. Oncol. 35, 834-841.

Torre, L.A., Bray, F., Siegel, R.L., Ferlay, J., Lortet-Tieulent, J., Jemal, A., 2015. Global cancer statistics, 2012. CA Cancer J. Clin. 65, 87-108.

UBOS, 2014. In: Statistics UBo (Ed.), Uganda National Household Survey 2012/2013. Kampala, Uganda.

Wabinga, H., Ramanakumar, A.V., Banura, C., Luwaga, A., Nambooze, S., Parkin, D.M., 2003. Survival of cervix cancer patients in Kampala, Uganda: 1995-1997. Br. J. Cancer 89, 65-69.

Walusansa, V., Okuku, F., Orem, J., 2012. Burkitt lymphoma in Uganda, the legacy of Denis Burkitt and an update on the disease status. Br. J. Haematol. 156, 757-760.

Warner, L.C., 2017. Lab-in-a-box. Am. J. Clin. Pathol. 147, 8-14.

WHO, 2013. Comprehensive Cervical Cancer Prevention and Control: A Healthier Future for Girls and Women. World Health Organization, Geneva.

Yap, M.L., Hanna, T.P., Shafiq, J., Ferlay, J., Bray, F., Delaney, G.P., et al., 2017. The benefits of providing external beam radiotherapy in low- and middle-income countries. Clin. Oncol. 29, 72-83.

Zdenkowski, N., Cavenagh, J., YC, Ku, Bisquera, A., Bonaventura, A., 2013. Administration of chemotherapy with palliative intent in the last 30 days of life: the balance between palliation and chemotherapy. Intern. Med. J. 43, 1191-1198. 